\title{
Carbohydrate restriction improves the features of Metabolic Syndrome. Metabolic Syndrome may be defined by the response to carbohydrate restriction Jeff S Volek ${ }^{1}$ and Richard D Feinman*2
}

Address: ${ }^{1}$ Human Performance Laboratory, Department of Kinesiology, University of Connecticut, Storrs, CT 06269-1110 USA and ${ }^{2}$ Department of Biochemistry, SUNY Downstate Medical Center, Brooklyn, NY 11203 USA

Email: Jeff S Volek - jeff.volek@uconn.edu; Richard D Feinman* - rfeinman@downstate.edu

* Corresponding author

Published: 16 November 2005

Nutrition \& Metabolism 2005, 2:31 doi:|0.1 |86/|743-7075-2-31
Received: 25 October 2005

Accepted: 16 November 2005

This article is available from: http://www.nutritionandmetabolism.com/content/2/I/3 I

(c) 2005 Volek and Feinman; licensee BioMed Central Ltd.

This is an Open Access article distributed under the terms of the Creative Commons Attribution License (http://creativecommons.org/licenses/by/2.0), which permits unrestricted use, distribution, and reproduction in any medium, provided the original work is properly cited.

\begin{abstract}
Metabolic Syndrome (MetS) represents a constellation of markers that indicates a predisposition to diabetes, cardiovascular disease and other pathologic states. The definition and treatment are a matter of current debate and there is not general agreement on a precise definition or, to some extent, whether the designation provides more information than the individual components. We consider here five indicators that are central to most definitions and we provide evidence from the literature that these are precisely the symptoms that respond to reduction in dietary carbohydrate $(\mathrm{CHO})$. Carbohydrate restriction is one of several strategies for reducing body mass but even in the absence of weight loss or in comparison with low fat alternatives, $\mathrm{CHO}$ restriction is effective at ameliorating high fasting glucose and insulin, high plasma triglycerides (TAG), low $\mathrm{HDL}$ and high blood pressure. In addition, low fat, high CHO diets have long been known to raise TAG, lower HDL and, in the absence of weight loss, may worsen glycemic control. Thus, whereas there are numerous strategies for weight loss, a patient with high BMI and high TAG is likely to benefit most from a regimen that reduces $\mathrm{CHO}$ intake. Reviewing the literature, benefits of $\mathrm{CHO}$ restriction are seen in normal or overweight individuals, in normal patients who meet the criteria for MetS or in patients with frank diabetes. Moreover, in low fat studies that ameliorate LDL and total cholesterol, controls may do better on the symptoms of MetS. On this basis, we feel that MetS is a meaningful, useful phenomenon and may, in fact, be operationally defined as the set of markers that responds to $\mathrm{CHO}$ restriction. Insofar as this is an accurate characterization it is likely the result of the effect of dietary $\mathrm{CHO}$ on insulin metabolism. Glucose is the major insulin secretagogue and insulin resistance has been tied to the hyperinsulinemic state or the effect of such a state on lipid metabolism. The conclusion is probably not surprising but has not been explicitly stated before. The known effects of $\mathrm{CHO}$-induced hypertriglyceridemia, the HDL-lowering effect of low fat, high $\mathrm{CHO}$ interventions and the obvious improvement in glucose and insulin from $\mathrm{CHO}$ restriction should have made this evident. In addition, recent studies suggest that a subset of MetS, the ratio of TAG/HDL, is a good marker for insulin resistance and risk of CVD, and this indicator is reliably reduced by $\mathrm{CHO}$ restriction and exacerbated by high $\mathrm{CHO}$ intake. Inability to make this connection in the past has probably been due to the fact that individual responses have been studied in isolation as well as to the emphasis of traditional therapeutic approaches on low fat rather than low $\mathrm{CHO}$.

We emphasize that MetS is not a disease but a collection of markers. Individual physicians must decide whether high LDL, or other risk factors are more important than the features of MetS in any individual case but if MetS is to be considered it should be recognized that reducing $\mathrm{CHO}$ will bring improvement. Response of symptoms to $\mathrm{CHO}$ restriction might thus provide a new experimental criterion for MetS in the face of on-going controversy about a useful definition. As a guide to future research, the idea that control of insulin metabolism by $\mathrm{CHO}$ intake is, to a first approximation, the underlying mechanism in MetS is a testable hypothesis.
\end{abstract}




\section{Introduction}

An association between obesity, diabetes, cardiovascular disease and hypertension has been recognized for some time. Reaven's 1988 Banting lecture is generally considered a turning point in codifying a unifying principle under the name of MetS or Syndrome X (Reviews: [1-7]. Although there is no universally accepted definition or mechanism, (Table 1) a rough common denominator is the set of five features: obesity (high body weight, BMI and/or waist circumference), high glucose and insulin levels, low HDL, high TAG and high blood pressure. Involvement of insulin resistance is generally a common feature and a likely causative agent for at least some of the symptoms. A subset of these metabolic markers, the TAG:HDL ratio, has been proposed as a simple marker for identifying insulin resistance [8]. It has recently been questioned whether the risk attributed to MetS is greater than the sum of the individual symptoms [9] and, ironically, Reaven has taken the "Con" side on a debate on the viability and diagnostic usefulness of the concept $[10,11]$. Nonetheless, there seems little controversy on the inherent potential for risk in the individual components.

In reading recent reviews of low $\mathrm{CHO}$ diets [12,13], we were struck by the fact that the symptoms of MetS are precisely the ones targeted by diets that restrict $\mathrm{CHO}$. This effect is not entirely surprising since it has been known that dietary CHO tends to raise glucose, insulin, and TAG and lower HDL and conversely, replacing $\mathrm{CHO}$ with monounsaturated fat or with fat and protein improves glycemic control and dyslipidemia expressed as elevated TAG and lowered HDL. Nevertheless, most formal guidelines and clinical papers have not emphasized $\mathrm{CHO}$ restriction as a viable approach to treating MetS or the individual components [14,15] and although several authors have indicated an association between MetS and $\mathrm{CHO}$ restriction in passing $[5,13,16,17]$ the explicit connection has not been made.
In this study we have isolated five features that are common to almost all definitions. Waist circumference is probably the currently preferred measure for obesity, but most of the literature provides data on body mass and we have used that measure. We have collected information in the literature supporting the notion that these symptoms are specifically ameliorated by reduction in dietary $\mathrm{CHO}$, and to the extent that they have been directly compared, low $\mathrm{CHO}$ strategies appear to have an advantage over low fat diets or simple calorie reduction. We conclude that response to $\mathrm{CHO}$ restriction may be an operational definition for MetS and that a likely mechanism is the control of insulin metabolism. Finally, we side with those who maintain that MetS is a real thing in the sense that the concomitant appearance of several symptoms may provide different recommended strategies than the isolated factors. It is important to point out, however, that MetS is not a disease but a complex of markers and practitioners may decide that LDL or other factors are more important for individual patients and in these cases other therapies will be appropriate. On the other hand, reliance on LDL as a prime indicator must be tempered by the importance of LDL particle phenotypes which, in turn, correlate with TAG and HDL levels, a subset of MetS markers.

\section{CHO restriction for weight loss}

It is sometimes stated that MetS is caused by obesity [1]. In our view, this is only one of several possible theories and would assume that we know the causes of obesity. It is at least plausible that obesity and the features of MetS arise in parallel from disruptions of insulin metabolism (possibly a consequence of high insulin due to chronic high dietary $\mathrm{CHO}$ ). Also a high prevalence of so called metabolically obese-normal-weight individuals with MetS has long been known [18]. In any case, it is generally agreed that the first line of attack against MetS or frank diabetes should be reduction in body mass. The method for attaining this weight loss, however, is more controver-

Table I: NCEP-ATP III and WHO Definitions of Metabolic Syndrome. Other definitions in references [I], [4] and [90].

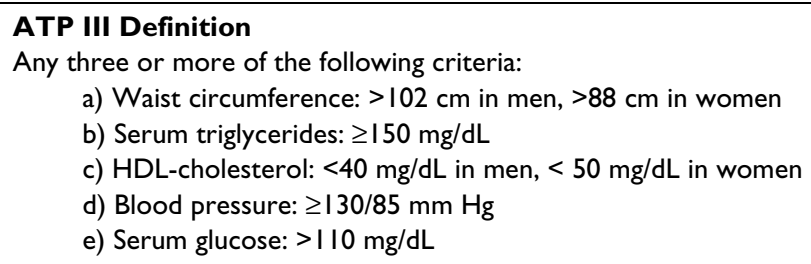

\section{WHO Definition}

Diabetes or IFG or IGT or insulin resistance, plus at least two of the following criteria

a) Waist-to-hip ratio: $>0.90$ in men, $>0.85$ in women

b) Serum triglycerides: $>150 \mathrm{mg} / \mathrm{dL}$ or HDL-cholesterol: $<35 \mathrm{mg} / \mathrm{dL}$ in men and $<40 \mathrm{mg} / \mathrm{dL}$ in women

c) Blood pressure: $>140 / 90 \mathrm{mmHg}$

d) Urinary albumin excretion rate $>20 \mu \mathrm{g} / \mathrm{min}$ or albumin/creatinine ratio $>30 \mathrm{mg} / \mathrm{g}$ 
Table 2:

\begin{tabular}{|c|c|c|c|c|c|c|c|c|c|c|}
\hline \multirow[b]{2}{*}{ Reference } & \multirow[b]{2}{*}{$\#$} & \multirow[b]{2}{*}{ Subjects } & \multirow[b]{2}{*}{ Duration } & \multicolumn{7}{|c|}{ CHANGE } \\
\hline & & & & $\mathrm{CHO}(\mathrm{g} / \mathrm{d})$ & weight (\%) & HDL (\%) & TAG (\%) & TAG/HDL (\%) & Glucose (\%) & Insulin (\%) \\
\hline Rickman et al. 1974 & 1 & Normal Weight Men/Women & $3-17 d$ & 7 & -4.9 & & $-I I .4$ & & & \\
\hline LaRosa et al. 1980 & 2 & Obese Men/Women & $8 w k$ & 6 & -8.3 & -5.7 & -32.6 & -29.9 & & \\
\hline Phinney et al. 1980 & 3 & Obese Men/Women & 6 wk & $<20$ & -11.8 & & -24 & & -16.3 & -57.3 \\
\hline Phinney et al. 1983 & 4 & Normal Weight Men & 4 wk & $<20$ & 0.2 & 0 & -26 & & -7.7 & -23.3 \\
\hline Newbold, 1988 & 5 & Men & $3-12 \mathrm{mo}$ & & & 9.6 & -34.8 & -40.5 & & \\
\hline Volek et al. 2000 & 6 & Normal Weight Men & $8 w k$ & 39 & -5.4 & 10.0 & -54.9 & -56.9 & -3.4 & -28.0 \\
\hline Sharman et al. 2002 & 7 & Normal Weight Men & 6 wk & 46 & -2.8 & $I I .5$ & -33 & -39.9 & -0.2 & -34.2 \\
\hline Meckling et al. 2002 & 8 & Obese Women & $8 w k$ & 71 & -6.1 & 4.3 & -40.3 & & -4.1 & 0.0 \\
\hline Westman et al. 2002 & 9 & Obese Men/Women & $6 \mathrm{mo}$ & Ad Lib & -10.3 & 19.2 & -43.1 & -53.6 & & \\
\hline Dashti et al. 2003 & 10 & Obese Men/Women & $12 \mathrm{wk}$ & 20 to 30 & -13.4 & 8.3 & -50 & -53.9 & -37.1 & \\
\hline \multirow[t]{3}{*}{ Hays et al. 2003} & 11 & Obese Men/Women w/ CVD & $6 w k$ & Ad Lib & -5.2 & -2.9 & -39.9 & -38.1 & -7.4 & -30.5 \\
\hline & & Obese Women PCOS & $24 w k$ & Ad Lib & -14.3 & 0.4 & -18.5 & -18.8 & 5.7 & -49.6 \\
\hline & & Obese Women Reactive Hypoglycemia & $52 w k$ & Ad Lib & -19.9 & 3.4 & -13.3 & -33.2 & & \\
\hline Dashti et al. 2004 & 12 & Obese Men/Women & $24 \mathrm{wk}$ & 40 & -14.2 & 20.4 & -60.4 & -67.1 & -22.6 & \\
\hline Boden et al. 2005 & 13 & Obese/diabetic men/women & 14 days & 21 & -1.8 & -2 & -35 & -33.8 & -16.0 & \\
\hline
\end{tabular}

Table 3:

\begin{tabular}{|c|c|c|c|c|c|c|c|c|c|c|c|}
\hline \multirow[b]{2}{*}{ Reference } & \multirow[b]{2}{*}{$\#$} & \multirow[b]{2}{*}{ Subjects } & \multirow[b]{2}{*}{ Duration } & \multirow[b]{2}{*}{ Diet } & \multicolumn{7}{|c|}{ CHANGE } \\
\hline & & & & & $\mathrm{CHO}(\mathrm{g} / \mathrm{d})$ & weight (\%) & HDL (\%) & TAG (\%) & TAG/HDL (\%) & Glucose (\%) & Insulin (\%) \\
\hline \multirow[t]{2}{*}{ Sharman et al.2002 } & 1 & Normal Weight Men & $6 \mathrm{wk}$ & Ketogenic & 46 & -2.8 & 11.5 & -33.0 & -39.9 & -0.2 & -34.2 \\
\hline & & & $6 w k$ & Low-Fat & 271 & 0.5 & 0.0 & -5.3 & -5.3 & 1.8 & 13.0 \\
\hline \multirow[t]{2}{*}{ Volek et al. 2003} & 2 & Normal Weight Women & 4 wk & Ketogenic & 43 & -2.0 & 32.0 & -30.2 & -47.2 & -1.9 & 11.6 \\
\hline & & & 4 wk & Low-Fat & 249 & -1.3 & -7.7 & 3.8 & 0.5 & -5.3 & 18.7 \\
\hline \multirow[t]{2}{*}{ Allick et al. 2004} & 3 & Type 2 Diabetics & $2 w k$ & Ketogenic & 0 & 0 & 23.5 & -43.9 & -55 & -16.9 & -16.7 \\
\hline & & & $2 w k$ & Low-Fat & 775 & & & & & & \\
\hline
\end{tabular}


sial. Studies in the literature imply that a low fat diet is a kind of standard although much recent evidence has indicated the value of strategies based on carbohydrate restriction. Whereas low fat diets for calorie reduction can undoubtedly be effective for many people, we feel that they cannot be taken as an established standard; to our knowledge, there has never been a long term study where a low fat diet was instituted in the absence of confounding features such as cessation of smoking and exercise. Also, fat restriction per se does not enhance long-term (one year or longer) weight loss or prevent regain of weight [19] and the record of compliance is modest at best [20]. Most important, the fact that, in the obesity and diabetes epidemic, fat consumption went down (for men, the absolute amount) and carbohydrate consumption went up $[21,22]$, means that other approaches should be considered. Insofar as isocaloric comparisons have been made, low $\mathrm{CHO}$ diets do at least as well, and usually better, than low fat diets (see below). Most striking, in ad lib. trials, subjects on low $\mathrm{CHO}$ diets show a spontaneous reduction in calories without any dissatisfaction [23-25], a goal that is universally considered desirable but generally recognized as difficult to impose by cognitive admonitions on calorie restriction per se [26]. In general, published data support the idea that low $\mathrm{CHO}$ diets are at least as effective as other weight reduction methods. Further, experimental results show an improvement in lipid outcomes (discussed below), no damage to normal kidneys [27], the potentially beneficial rather than deleterious effects of ketone bodies [28-30] and the prevalence of strategies based on low glycemic index $[31,32]$ or reduction of refined $\mathrm{CHO}$ or sweets, all approximations of low $\mathrm{CHO}$ diets.

Despite increased acceptance of low carbohydrate regimens, it is important to point out that there is a tendency to equate any kind of carbohydrate restriction with the popular Atkins diet [33] and to equate the Atkins diet with a recommendation for high fat and with high saturated fat, in particular. There are, however, many strategies for reducing carbohydrate intake both clinically and in popular diets [34,35]. Whereas high fat is permitted on the Atkins diet and other low carbohydrate diets it is not specifically recommended; as noted above, at least three published studies [23-25] and much anecdotal evidence suggests that, in practice, the major effect is reduction in carbohydrate intake with limited replacement with either fat or protein. In addition, although a deleterious effect of saturated fat, at least in the absence of $\mathrm{CHO}$ control, is established [36,37], it has been known since the Seven Countries study [38] that total dietary fat does not correlate with cardiovascular risk and the two effects should not be confused [36,37]. In any case, no particular diet is recommended here; the studies cited include all kinds of interventions, and the underlying rationale is the effect of carbohydrate on insulin. The principle espoused here should be evaluated on this basis.

It seems that a prudent statement of the state of affairs would be that, at this point, dieters have many strategies, none perfect, for weight loss and $\mathrm{CHO}$ restriction of some kind is one of them.

\section{$\mathrm{CHO}$ restriction and MetS}

Our argument in the following exposition is that a patient presenting with a high BMI or large waist line has several options for weight loss. Many factors, including physician experience, ethnic background, personal taste and genetic profile, will determine the first one to be tried. A patient presenting with high BMI and high TAG may have a clear best strategy because of the known benefit of $\mathrm{CHO}$ reduction and the accepted deleterious effect of high $\mathrm{CHO}$ intake. Data from the literature suggests that a patient with more than two of the symptoms of MetS or the particular combination of high TAG/HDL ratio should clearly try $\mathrm{CHO}$ restriction as a first strategy. Conversely, the patient with high BMI and high LDL might sensibly try a low fat strategy first. We provide a summary of cases in which $\mathrm{CHO}$ restriction is beneficial in the treatment of MetS or its individual symptoms. The review is meant to be representative rather than comprehensive but we think that the wide variety of cases studied and the range of conditions against a background of accepted effects of carbohydrate on the relevant parameters, provides a strong case for our thesis. In addition, the generally consistent benefit of $\mathrm{CHO}$ restriction allows a possible further basis for identifying the common thread in MetS if such truly exists.

\section{$\mathrm{CHO}$ restriction improves symptoms of MetS}

Table 2 (Table 2) shows the results of single arm studies in which CHO-restricted diets of various compositions and duration were used (for summary of details see, e.g., [39-41]). The regimens include very low $\mathrm{CHO}$ ketogenic diets $(<50 \mathrm{~g} / \mathrm{d})$ and encompasses subjects that were overweight, presented with symptoms of MetS, or were diabetic. It is clear that $\mathrm{CHO}$ restriction is effective in relieving these symptoms. Noteworthy is the recent study of Boden [23] which, while short in duration, carefully measured relevant parameters in patients with diabetes. Patients in this study spontaneously decreased food intake to a substantial degree, were satisfied with the diet, did not show substantial water loss and several were able to reduce or terminate medication.

\section{Improvement is seen in the absence of weight loss}

Since it is known that weight loss generally improves MetS, it is important to ask whether beneficial metabolic responses to low $\mathrm{CHO}$ diets are dependent on weight loss. The question was specifically addressed by Volek's group $[42,43]$ in normal-weight men and women encouraged to 


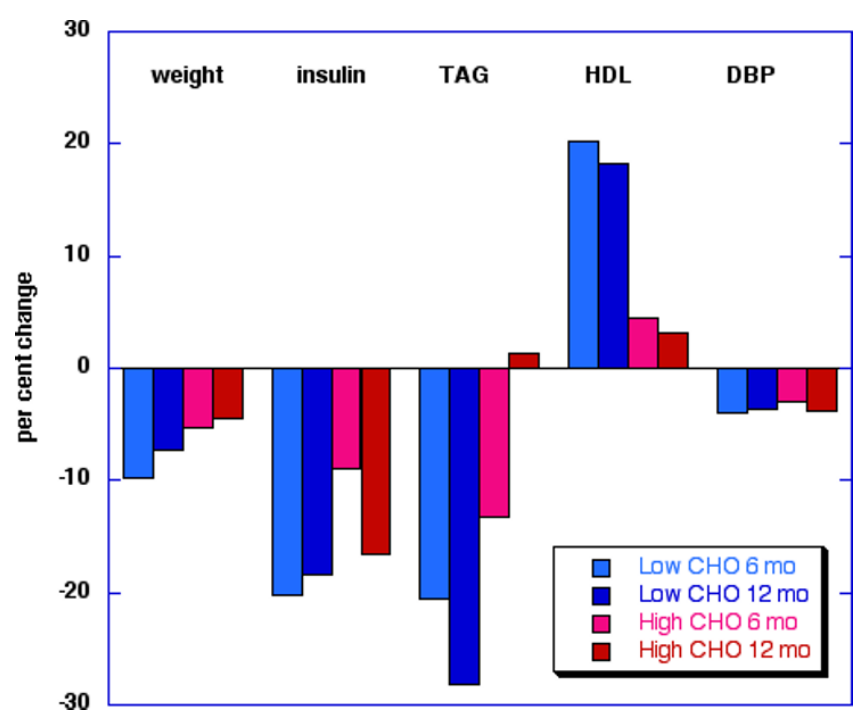

Figure I

Comparison of features of Metabolic Syndrome on low carbohydrate vs. high carbohydrate diets. Data from reference [45]. maintain their weight and by Allick and colleagues in patients with diabetes mellitus type 2 [44] (Table 3). The studies in normal weight women [43] and type 2 diabetics [44], in particular, used a cross-over experimental design removing the confounding effect of group differences. These studies were also well-controlled. In the case of Allick, formula was used and, in the studies by Volek, compliance was documented by measuring elevation of serum and urine ketones, thereby eliminating dietary reporting errors as a confounding factor. Improvement in the TAG/HDL ratio ranged from 40 to 55\%. In summary, a low $\mathrm{CHO}$ regimen clearly improves MetS relative to low fat diets even in the absence of weight loss.

In addition to studies in which weight maintenance was a feature of experimental design it is important to consider data reported by Foster [45] (Figure 1, (Table 4), who compared low $\mathrm{CHO}$ and LF diets. It is widely quoted that the low $\mathrm{CHO}$ diet is better at 6 months but that there is no difference in the diets at 12 months. However, it has been pointed out [12] that the particular form of low $\mathrm{CHO}$ diet used (Atkins diet) allowed increases in CHO consumption as the trial progressed indicating that it is likely this reintroduction of $\mathrm{CHO}$ that predisposes to long-term regain in weight. Most notable in this study, is that the improvement in lipid profile persisted (Figure 1, (Table 4) even after the effect on weight loss disappeared.
In ad lib. comparisons low $\mathrm{CHO}$ diets do better than low fat diets for weight loss and MetS

At this point, we have established that $\mathrm{CHO}$ restriction improves MetS and that this can be independent of weight loss. Weight loss can, of course, occur with low fat diets and we next consider the extent to which one or the other strategy is more effective. (Table 4) summarizes results of several studies in the literature demonstrating that low CHO diets generally do better than low fat diets in ad lib. comparisons. Although there is great variability, a pattern of better responses on very low $\mathrm{CHO}$ is evident. It is notable that Samaha et al studied a population in which $39 \%$ had diabetes and 43\% had MetS [46].

Figure 1 shows data from the study of Foster, et al. [45] and, as noted above, despite the relative similarity in weight loss, the markers of MetS were more favorable in the low CHO arm than the LF arm.

\section{In isocaloric comparisons, low CHO diets do better than LF diets for weight loss}

Because weight reduction is considered the first line of attack in MetS or frank diabetes it is worth considering the record of low $\mathrm{CHO}$ diets on this parameter alone. It is generally agreed that the major effect of a low $\mathrm{CHO}$ diet is a spontaneous reduction in calories. In studies mentioned above, subjects did not significantly increase fat or protein intake but merely removed CHO from their diets [23-25]. Foster and Samaha also attributed the better performance of low $\mathrm{CHO}$ arm to decreased caloric intake, although this was not actually measured.

Beyond spontaneous caloric reduction, however, it has been shown that the macronutrient composition of the diet can affect the efficiency of energy utilization and greater efficacy, the so-called metabolic advantage, of low CHO diets compared to LF diets has been the subject of several reports (Reviews: [39,41]. It has long been argued that there must be some mistake because it is physically impossible and would violate the laws of thermodynamics. We have shown this argument is based on misunderstanding of the laws of thermodynamics [39,47-49] and the effect of variable efficiency is now better accepted $[50,51]$. The precise conditions that allow the so-called metabolic advantage to occur are not known although Cornier, et al. [51] have suggested that those subjects with insulin resistance will show a metabolic advantage on a low $\mathrm{CHO}$ diet whereas those who are insulin sensitive do better on low fat. This is consistent with the proposal here, namely that MetS, where insulin-resistance is generally considered a major component, can be defined by the response to $\mathrm{CHO}$ restriction. The study of Cornier, et al. [51] had only a small number of subjects and the low $\mathrm{CHO}$ arm was not particularly low (40\%) but their theory follows from the general rationale of the effect of $\mathrm{CHO}$ on 
Table 4:

\begin{tabular}{|c|c|c|c|c|c|c|c|c|c|c|c|c|}
\hline \multirow[b]{2}{*}{ Reference } & \multirow[b]{2}{*}{$\#$} & \multirow[b]{2}{*}{ Subjects } & \multirow[b]{2}{*}{ Duration } & \multirow[b]{2}{*}{ Diet } & \multicolumn{8}{|c|}{ CHANGE } \\
\hline & & & & & $\mathrm{CHO}(\mathrm{g} / \mathrm{d})$ & weight (\%) & HDL (\%) & TAG (\%) & TAG/HDL (\%) & Glucose (\%) & Insulin (\%) & $\begin{array}{c}\text { DBP } \\
(\mathrm{mm} \mathrm{Hg})\end{array}$ \\
\hline \multirow{2}{*}{ Brehm et al. 2003} & 1 & Obese Women & $6 \mathrm{mo}$ & Low-CHO & $4 I-97$ & -9.3 & 13.4 & -23.4 & -32.4 & -9.1 & -14.8 & -5 \\
\hline & & & & LF & $163-169$ & -4.2 & 8.4 & 1.6 & -6.3 & -4.0 & -23.0 & -1 \\
\hline \multirow[t]{2}{*}{ Sondike et al. 2003} & 2 & Overweight Adolescents & $12 \mathrm{wk}$ & Low-CHO & 37 & -10.7 & 8.7 & -40.5 & -45.2 & & & \\
\hline & & & & LF & 154 & -4.1 & 4.2 & -5.4 & -9.2 & & & \\
\hline \multirow[t]{2}{*}{ Samaha et al. 2003} & 3 & Obese Men/Women & $6 \mathrm{mo}$ & Low-CHO & 150 & -4.5 & 0.0 & -20.2 & -20.2 & -8.6 & -27.3 & \\
\hline & & & & LF & 201 & -1.4 & -2.4 & -4 & -1.6 & -1.6 & 5.6 & \\
\hline \multirow[t]{2}{*}{ Foster et al. 2003} & 4 & Obese Men/Women & $\mathrm{l} y \mathrm{r}$ & Low-CHO & ad lib & -7.3 & 18.2 & -28.1 & -29.5 & & & \\
\hline & & & & LF & ad lib & -4.5 & 1.4 & 0.7 & -2.6 & & & \\
\hline \multirow[t]{2}{*}{ Volek et al. 2004} & 5 & Overweight Women & 4 wk & Low-CHO & 29 & -3.9 & 1.3 & -23 & -28.3 & -3.8 & -8.8 & \\
\hline & & & & $\mathrm{LF}$ & 186 & -1.4 & -8.6 & -11.2 & -4.2 & 1.3 & 23.2 & \\
\hline \multirow[t]{2}{*}{ Sharman et al. 2004} & 6 & Overweight Men & $6 w k$ & Low-CHO & 36 & -5.6 & -3.3 & $-44 . I$ & -42.3 & -5.8 & $-4 I .5$ & \\
\hline & & & & $\mathrm{LF}$ & 224 & -3.6 & -6.6 & -15 & -8.3 & -5.2 & -28.1 & \\
\hline \multirow[t]{2}{*}{ Brehm et al. 2004} & 7 & Obese Women & $4 \mathrm{mo}$ & Low-CHO & 69 & -10.8 & 16.3 & -37.3 & $-46 . I$ & & & -9 \\
\hline & & & & $\mathrm{LF}$ & 174 & -6.8 & 4.5 & -10.3 & -14.2 & & & -3 \\
\hline \multirow[t]{2}{*}{ Meckling et al. 2004} & 8 & Obese Men/Women & $10 w k$ & Low-CHO & 59 & -7.7 & 12.2 & -29.4 & -37.1 & -8.0 & -28.7 & -6.1 \\
\hline & & & & LF & 225 & -7.4 & -15.4 & -25.4 & -11.8 & -10.2 & -3.3 & -5 \\
\hline \multirow[t]{2}{*}{ Stern et al. 2004} & 9 & Obese Men/Women & $\mathrm{l} y r$ & Low-CHO & 120 & -3.9 & -2.8 & -28.6 & -26.8 & & & \\
\hline & & & & LF & 230 & -2.3 & -12.3 & 2.7 & 29.6 & & & \\
\hline \multirow[t]{2}{*}{ Yancy et al. 2004} & 10 & Obese Men/Women & $24 \mathrm{wk}$ & Low-CHO & 30 & -12.3 & 9.8 & -47.2 & $-5 I .8$ & & & -6 \\
\hline & & & & LF & 198 & -6.7 & -2.9 & -14.4 & $-|2|$. & & & -5.2 \\
\hline \multirow[t]{2}{*}{ Aude et al. 2004} & 11 & Obese Men/Women & $12 \mathrm{wk}$ & Low-CHO & ad lib & -6.2 & -2.6 & -23.2 & $-2 I . I$ & & & \\
\hline & & & & LF & ad lib & -3.4 & -7 & -10.5 & -3.8 & & & \\
\hline \multirow[t]{2}{*}{ Seshadri et al. 2004} & 12 & Obese Men/Women & $6 \mathrm{mo}$ & Low-CHO & 113 & $(-8.5)$ & -2.4 & -7.4 & & & -40 & \\
\hline & & & & LF & 198 & $(-3.5 \mathrm{~kg})$ & -2.4 & -2.3 & & & 11.2 & \\
\hline \multirow[t]{3}{*}{ McAuley et al. 2004} & 13 & Obese Women & $8 w k$ & Low-CHO & $4 I$ & -6.9 & 0.9 & -38.8 & -44.2 & -5.9 & -39.3 & \\
\hline & & & & LF & 172 & -4.4 & -6 & -17.5 & $-|5|$. & -0.1 & -28.4 & \\
\hline & & & & Mod-PRO & 130 & -5.8 & -4.1 & -33.9 & -31.8 & -3.9 & -24.4 & \\
\hline \multirow[t]{4}{*}{ Dansinger et al. 2004} & 14 & Obese Men/Women & $2 \mathrm{mo}$ & Low-CHO & 103 & -4.7 & 8.8 & -27.6 & -26.20 & -10 & -29.5 & \\
\hline & & & & Mod-PRO & 158 & -4.6 & 4.6 & -34 & -30.50 & -9.3 & -27.7 & \\
\hline & & & & $\mathrm{LF}$ & 183 & -4.3 & -0.6 & -7.1 & -5.60 & -5.7 & -11 & \\
\hline & & & & UltraLF & 230 & -4.9 & -10.9 & -0.6 & 8.40 & -3.5 & -7.7 & \\
\hline
\end{tabular}




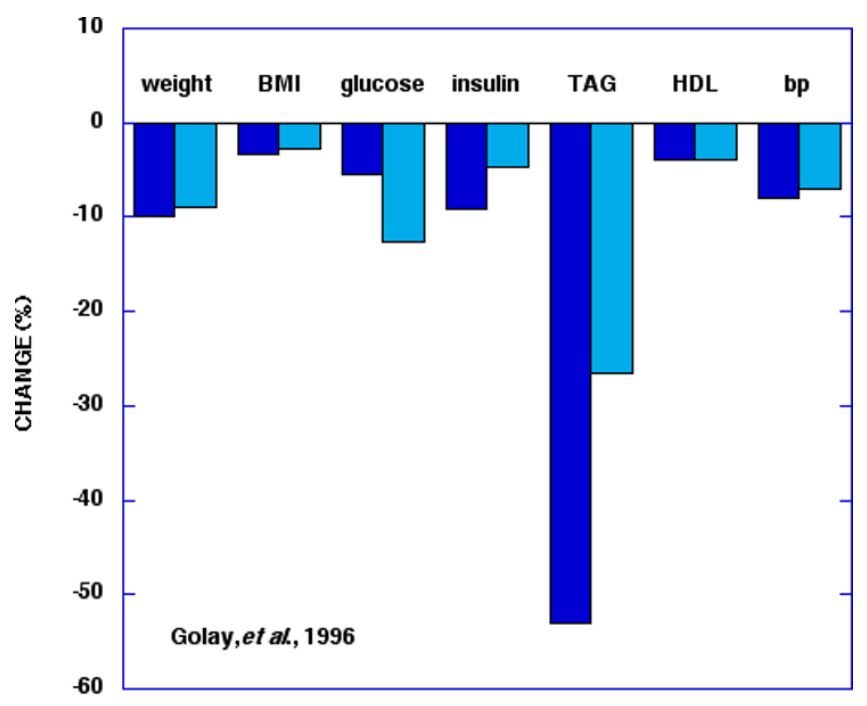

Figure 2

Per cent change in response to diet. Low carbohydrate (dark blue $25 \% \mathrm{CHO}$ ) and low fat diets(light blue: $45 \%$ $\mathrm{CHO}$ ). Data from Golay, et al. [52].

energy efficiency. The factors that determine whether a metabolic advantage can play a role in a $\mathrm{CHO}$ restricted diet is unknown but given that the insulin resistance association is reasonable, it would seem that some form of $\mathrm{CHO}$ restriction is one of the standard, if not preferred attacks on obesity where MetS is suspected.

Figure 2 shows data from Golay, et al. [52] This study is widely quoted as an example of how weight loss is independent of macronutrient composition; although the low $\mathrm{CHO}$ arm did better in weight loss, this was judged not significant. This may well be an experiment in which metabolic advantage does not occur - the effect is only possible, not required [39]. It is clear, however, from the figure that there is improvement in TAG and insulin and Golay's conclusion was that "...considering the greater improvement of fasting blood insulin, the glucose/insulin ratio and blood triglyceride, the low carbohydrate diet (25\%) could be more favourable in the long-term [52]."

\section{Is this new?}

In Edgar Allan Poe's detective story The Purloined Letter, the police search the apartment for a missing blackmail note [53]. In the end, Poe's detective, Auguste Dupin reveals that it had been in plain view on the fireplace all along. The effect of $\mathrm{CHO}$ reduction on the symptoms of MetS has, in fact, been visible for some time. In a classic review in 1986, Reaven demonstrated the relative effects of $40 \%$ and $55 \% \mathrm{CHO}$ [54]. Figure 3 shows data from that study: day long glucose, insulin and TAG levels were

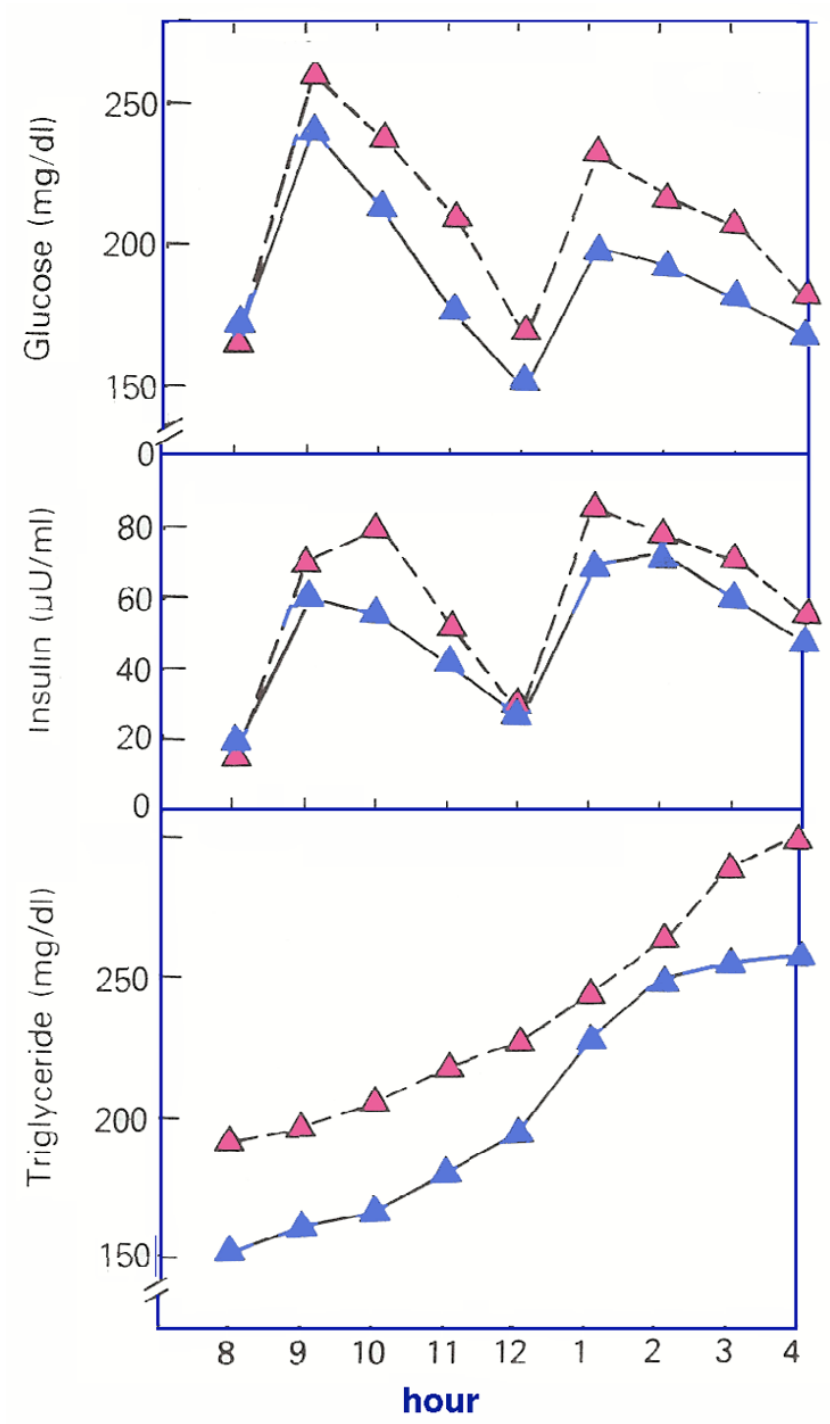

Figure 3

Effect of carbohydrate on parameters of Metabolic Syndrome. Comparison of $40 \% \mathrm{CHO}$ (blue) and 55\% (red) $\mathrm{CHO}$ diets. Data from [54].

improved by the low $\mathrm{CHO}$ diet. Of interest, is that fasting glucose is not different on the two diets but there is a clear difference in the time course, common to several low $\mathrm{CHO}$ interventions (Table 3)). Reaven's experiment suggests that a nutritional approach to MetS is possible by lowering dietary $\mathrm{CHO}$. The experiment should sensibly have spurred research to see whether still lower $\mathrm{CHO}$ had further beneficial effect. It took many years, however, before this was done.

\section{Substitution of protein for $\mathrm{CHO}$ improves MetS}

Despite the evidence from Reaven's experiment, a barrier to progress in understanding the role of $\mathrm{CHO}$ restriction 
was the accepted idea that high fat was unhealthy. At the same time, it was thought that an increase in protein would be deleterious for type 2 diabetics because of the increase in glucose due to gluconeogenesis. Nuttall and Gannon have summarized the history of this problem and work in their lab showed that, in fact, glycemic control was enhanced by a diet that was $40 \% \mathrm{CHO}$, with protein replacing part of the carbohydrate $[55,56]$. Most recently, this group has shown the benefit of a $20 \% \mathrm{CHO}$ diet with higher protein [57]. Results in Figure 4 show a pattern similar to Reaven's but much more dramatic. Similar striking differences in the control of insulin and TAG were also demonstrated.

Explicit low-fat/high CHO interventions exacerbate MetS In the approach taken here, we see dietary fat as playing a largely passive role (not withstanding differences between different fats) and the disposition of dietary fat is controlled by insulin and other hormones that, in turn, depend on dietary $\mathrm{CHO}$ which we take as the controlling variable. Thus, characterizing a low $\mathrm{CHO}$ diet as high fat $[58,59]$ ignores the question about the underlying mechanism; we have recently raised the question of whether "high fat" is a meaningful description in the absence of information about $\mathrm{CHO}[60]$. In the cases we discuss next, the focus is interventions described or designed as low fat. Our point here, however, is that although low fat diets exacerbate the markers of MetS, it is likely the high $\mathrm{CHO}$ rather than the fat level that is important.

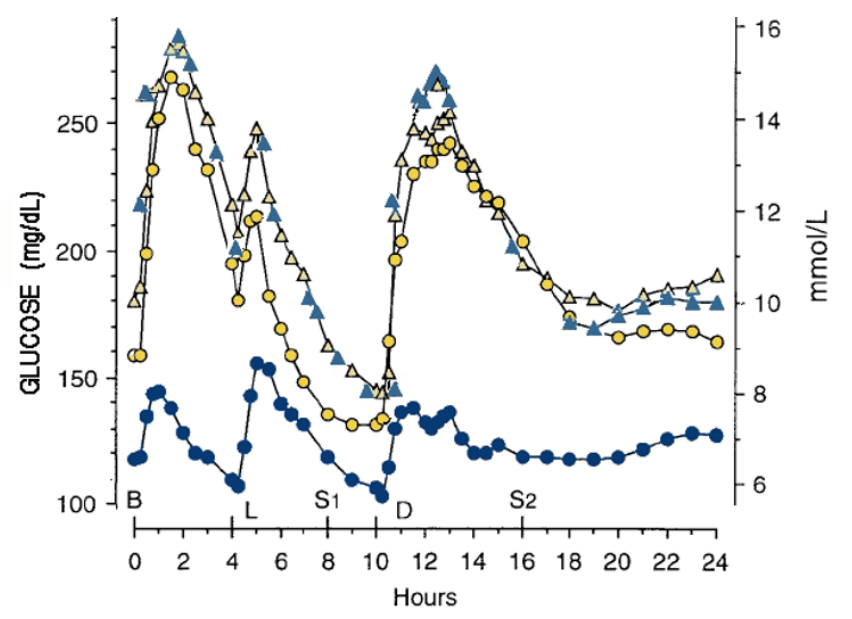

Figure 4

Effect of diet on plasma glucose. Mean plasma glucose concentration before (triangles) and after 5 weeks on control diet (yellow circles: (CHO:fat:protein $=55: 30: 15)$ ) or 5 weeks on lower carbohydrate diet (blue circles: (20:50:30)). Meal points are Breakfast (B), lunch (L) and dinner(D) plus 2 snacks (SI, S2). Data from reference [57].
A very influential paper by Garg, et al. [61] describes a four center randomized study of patients with type 2 diabetes receiving glipizide treatment. The study compared diets where monounsaturated fat was substituted for $\mathrm{CHO}$ or vice-versa. Because of its importance, we quote from this article. The rationale for the study, according to the authors is that:

"Compared with diets rich in saturated fats, low-fat, highcarbohydrate diets are reported to reduce serum low-density lipoprotein (LDL) cholesterol levels. Recent studies, however, suggest the high-carbohydrate diets may accentuate hypertriglyceridemia, reduce serum high-density lipoprotein (HDL) cholesterol concentration, and may even worsen hyperglycemia and/or raise plasma insulin levels."

In short, the question is whether high $\mathrm{CHO}$ diets worsen MetS. The conclusions of the paper state:

"The study confirms that HC (high carbohydrate diets) increase plasma TAG levels and increase VLDL-C concentrations in NIDDM patients. In this study the $\mathrm{HC}$ diet raised fasting plasma triglyceride levels and VLDL-C concentrations by $24 \%$ and $23 \%$ respectively compared with the HMUF diet. Furthermore, daylong levels of plasma triglycerides were also elevated on the high-carbohydrate diet. Consistent with the results of previous studies, plasma levels of total cholesterol and LDL cholesterol were not different on the two diets in this study. The study, therefore substantiates the fact that high carbohydrate diets offer no advantage in lowering LDL levels in NIDDM patients compared with high-fat diets that are low in saturated fats."

\section{The general case: substitution of fat for $\mathrm{CHO}$ improves MetS}

The substitution of fat for $\mathrm{CHO}$ is, in fact, generally beneficial for MetS. In a recent meta-analysis, Mensink, et al. [62] showed the effect of substitution of different fat sources or carbohydrate for the fat in the average US diet at $10 \%$ of energy. The conclusion was that substitution of carbohydrate had the most unfavorable response on the total cholesterol to HDL ratio, significantly worse than butter or palm oil (Figure 5).

\section{Summary of review and hypothesis to this point}

We have summarized work in the literature showing that low $\mathrm{CHO}$ interventions improve the markers of MetS in normal subjects, patients with MetS and diabetics. In comparative studies, they are at least as effective as low fat diets for weight loss and, tend to show better improvement in the other markers of MetS. Isocaloric studies similarly support the idea that the markers of MetS respond preferentially to low $\mathrm{CHO}$ diets. 


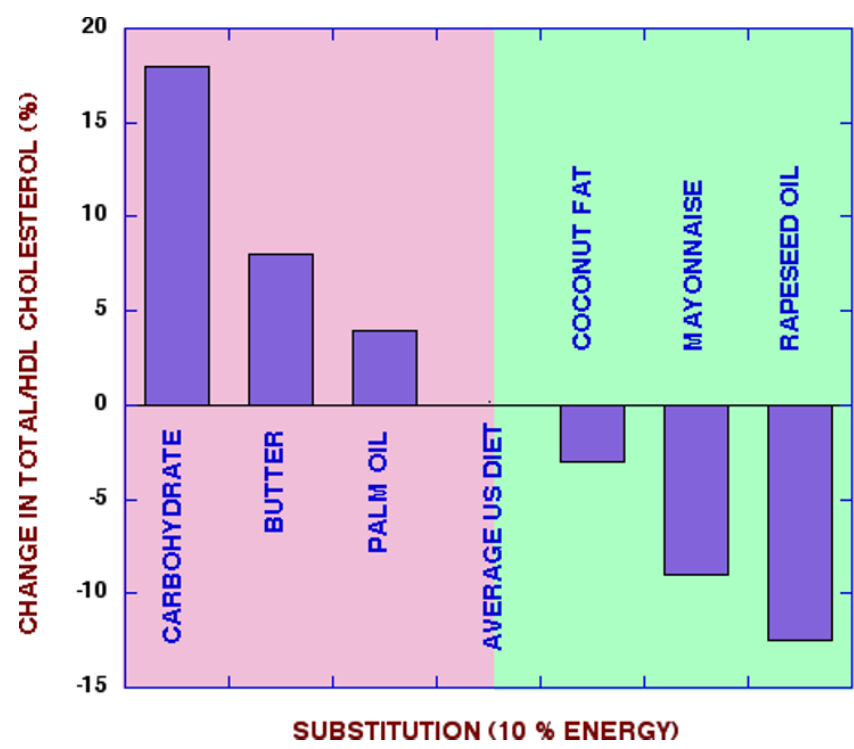

Figure 5

Changes in cholesterol/HDL for substitution for fat. Fat in the average American diet was substituted with the indicated substances at $10 \%$ of energy. Data from reference [62].

The state of accepted scientific thinking for the world at large is unknown but we have made the case that it is an acknowledged principle that low $\mathrm{CHO}$ diets tend to reduce TAG, raise HDL and improve glycemic control whereas $\mathrm{LF} /$ high $\mathrm{CHO}$ diets tend to have the opposite effect. Perhaps the strongest indication that such an idea is generally accepted is the paper by Rock, et al [63] where the effect of low fat diets in cancer patients was studied. To demonstrate compliance with the low fat recommendations, the authors showed increased TAG and reduced HDL levels. These effects were judged not significant enough to cause a risk for CVD but demonstrate that low fat (higher $\mathrm{CHO}$ ) diets point in that direction.

We reiterate that this article is not meant to make recommendations - for which many factors must be considered - but rather to show the association between CHO restriction and improvement in symptoms of MetS. Many low fat interventions have successfully reduced LDL, an established risk factor for CVD. If our hypothesis is correct, however, these same interventions should worsen the features of MetS. To some extent this is established from the principles noted above, but we provide an example from a well done experiment in the literature to support this corollary. Finally, in considering the dialectic of treating MetS with $\mathrm{CHO}$ restriction vs. high $\mathrm{LDL}$, with low fat diets, it is important to consider both individual variation and the role of LDL particle size. We consider that last.

\section{Studies of low-fat diets}

The most salient feature of the obesity epidemic from the standpoint of food consumption is the dramatic increase in $\mathrm{CHO}$ intake and the reduction in fat intake (for men, the absolute amount). To our knowledge, the decreased fat intake has not been accompanied by reduction in the incidence of CVD in unmedicated population. These data suggest that low fat diet recommendations per se are not likely to help MetS. If the fundamental idea proposed here is correct, then experimental interventions targeting lower fat that concomitantly raise $\mathrm{CHO}$ should, in fact, have a deleterious effect on the markers of MetS. Again, one will have to decide if the symptoms of MetS are more important than LDL or total cholesterol which are typically reduced on LF diets in the unmedicated population.

\section{Delta-I Study}

The Delta-1 study is one of the very well done trials involving a large number of participants [64]. The goal was to determine "the effects of reducing total fat and saturated fat" although this is slightly misleading in that only saturated fat was reduced and any reduction in total fat was a consequence of this. The randomized and balanced diets that were compared all contained approximately 15 $\%$ of calories as protein. Other macronutrients were as shown in Table 5. (Table 6) shows the outcomes for all groups on lipids in the Delta-1 study. The results indicate that LDL is significantly reduced although only SEM is given so that it is not possible to know the range of responses of subjects. As a group, however, there were step-wise reductions in LDL and HDL going from the average American diet (AAD) to Step 1 to the low saturated fat diet. There is, as well, a corresponding increase in TAG and hence the TAG/HDL ratio. The authors concluded that the reduction in LDL should be associated with $10 \%$ to $20 \%$ reductions in cardiovascular disease in the population. Other authors have argued, however, that the effect of the $13 \%$ higher HDL seen on the AAD might be associated with a $36 \%$ reduction in the risk of death from coronary disease or of myocardial infarction [65]. Again, the purpose here is not to decide on the relative risk attached to different markers but only to point out that the markers for MetS provide another side to the story. An important follow-up in the Delta study to determine HDL subpopulations [66], showed that the more anti-atherogenic $\mathrm{HDL}_{2}$ particles were, in fact, decreased by reductions in saturated fat.

The overall conclusion is that "dietary changes suggested to be prudent for a large segment of the population will primarily affect the concentrations of the most prominent antiatherogenic HDL subpopulation. However, the simultaneous reduction in the atherogenic LDL subpopulation will most likely offset any potential negative effect on cardiovascular risk." As noted above, the decision as to "most 
Table 5: Macronutrient composition of diets in the Delta-I study. Data from reference [64].

\begin{tabular}{lccccc}
\hline Diet & CHO (\%) & total fat (\%) & SFA (\%) & MUFA (\%) & PUFA (\%) \\
\hline Average American diet (AAD) & 48 & 34 & 15 & 13 & 7 \\
Step I & 55 & 29 & 9 & 13 & 7 \\
Low Saturated Fat & 59 & 25 & 6 & 12 & 7 \\
\hline
\end{tabular}

likely" outcome must rest with individual patients and physicians.

\section{Role of individual responses and LDL heterogeneity}

As noted in Garg's study, changes in LDL may not be as reliable as changes in other markers. Volek, et al. for example showed that whereas TAG was reduced in almost every subject on a low CHO diet, responses in LDL were highly variable [67]. The importance of LDL subpopulations has recently been appreciated and, unlike total $\mathrm{LDL}$, changes in specific LDL particles show a consistent pattern with respect to dietary change.

Greater atherogenic potential is associated with small, dense LDL particles [68]. Krauss and coworkers have carried out impressive work in defining the variability in different individuals. They identified a genetically influenced pattern (B) in people whose plasma contains small LDL particles. This subpopulation, typically $30 \%$ of the American population, responded to low-fat diets by lowering LDL but the pattern B persisted [69]. The remaining subpopulation with larger buoyant particles (pattern A) responded to reduction in fat intake by a shift to the more atherogenic pattern $\mathrm{B}$. Thus, for most of the populations studied, replacing dietary fat with $\mathrm{CHO}$ leads to a worsening of the LDL size distribution [70]. In a study described in reference [70], similar effects were seen when protein was substituted for carbohydrate without significant change in the fat content or composition. As summarized by Krauss, "This indicates that carbohydrate rather than fat is a major dietary determinant of expression or phenotype B in susceptible individuals." Although probably a semantic point, "susceptible" is redundant and describing pattern $\mathrm{A}$ and $\mathrm{B}$ as phenotypes may not be precise: Krauss has summarized how the relative amounts of $\mathrm{CHO}$ and fat affect the prevalence of pattern $\mathrm{B}$ [71] and the conclusion is that a strong relation exists between $\mathrm{CHO}$ intake (ranging from 40 to $75 \%$ ) and the prevalence of the pattern B phenotype (Fig 6). In other words, there appears to be a continuous variability in phenotype characterized by sensitivity to $\mathrm{CHO}$ and everyone may be susceptible to conversion to pattern $\mathrm{B}$ at some $\mathrm{CHO} /$ fat ratio. The extrapolated line in Figure 6 suggests that a truly low $\mathrm{CHO}$ diet might reduce the level of atherogenic subtype to zero. Thus, whereas we have described the dialectic in practical applications as balancing the improvement in MetS with $\mathrm{CHO}$ restriction and the improvement in LDL from lowfat diets, focusing on LDL may have some caveats. In general, a growing body of work has shown improvement in LDL pattern switching from high $\mathrm{CHO}$ to low $\mathrm{CHO}$ diets $[42,43,72-75]$.

The pattern B phenotype rarely occurs in isolation and, our major concern here is that it is metabolically linked to and co-expressed with other characteristics of MetS, particularly elevated TAG and low HDL. Krauss and colleagues reported that switching from a low $\mathrm{CHO} /$ high-fat diet ( $46 \%$ fat) to a high $\mathrm{CHO} /$ low-fat diet (26\% fat) resulted in lowering of LDL, but also a worsening of TAG and HDL when switching to the low fat diet [69]. In men that were pattern A at a fat intake of 20 to $24 \%$, a further reduction in dietary fat to $10 \%$ and $\mathrm{CHO}$ to $76 \%$ of energy resulted in conversion to $\mathrm{B}$, with continued worsening of TAG and HDL, and no additional LDL-lowering [76].

Table 6:

\begin{tabular}{|c|c|c|c|c|c|c|c|c|}
\hline \multirow[b]{2}{*}{ Ginsberg, et al., 1998 reference [64] } & \multicolumn{3}{|c|}{ Ave American Diet vs. Step I } & \multicolumn{5}{|c|}{ Ave American Diet vs. Low Sat Fat } \\
\hline & AAD & Step I & delta & $\%$ change & pre & post & delta & $\%$ change \\
\hline Total cholesterol & 202.1 & 191 & -11.1 & -5.5 & 202.1 & 183.4 & -18.7 & -9.3 \\
\hline LDL & 131.4 & 122.2 & -9.2 & -7.0 & 131.4 & 116.9 & -14.5 & -11.0 \\
\hline TAG (mmol/l) antiln (log) & 85.1 & 92.4 & 7.3 & 8.6 & 85.1 & 93 & 7.9 & 9.3 \\
\hline $\mathrm{HDL}(\mathrm{mmol} / \mathrm{l})$ & 52.2 & 48.5 & -3.7 & -7.1 & 52.2 & 46.2 & -6.0 & $-I I .5$ \\
\hline Total/HDL & 4.1 & 4.16 & 0.1 & 2.2 & 4.1 & 4.21 & 0.1 & 3.4 \\
\hline TAG/HDL (arbitrary units) & 1.6 & 1.9 & 0.3 & 16.9 & 1.6 & 2.0 & 0.4 & 23.5 \\
\hline
\end{tabular}




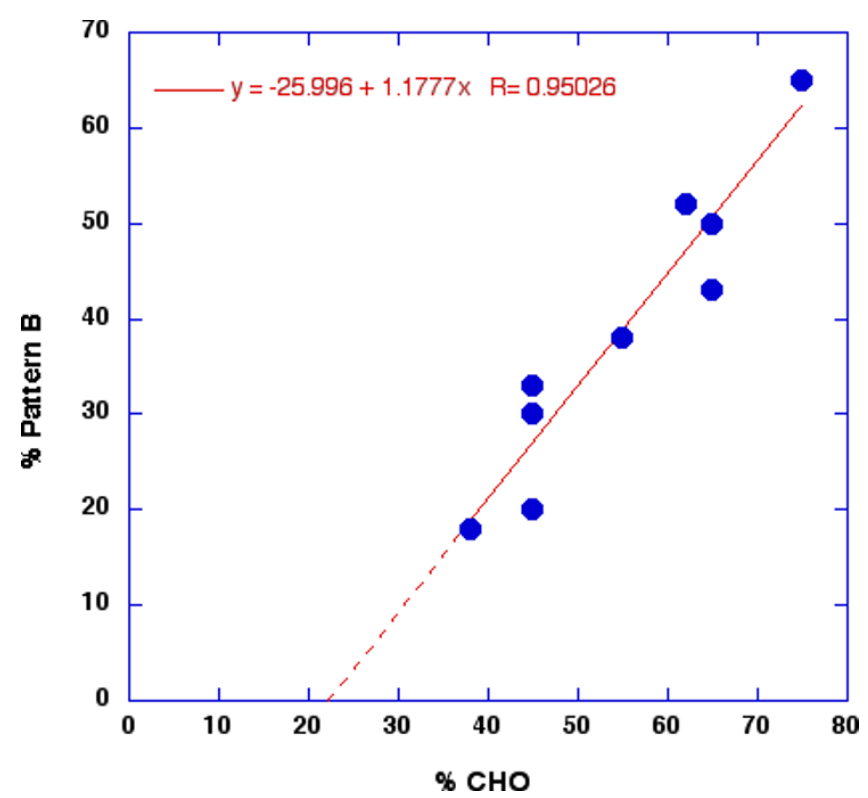

Figure 6

Prevalence of pattern B phenotype as a function of the percentage dietary $\mathrm{CHO}$ in men. Data from reference [7I].

\section{The TAG/HDL connection}

In the search for markers for both insulin resistance and predisposition to CVD, recent research has focused on the value of the ratio of TAG:HDL. McLaughlin, et al. [8] have shown a correlation between insulin resistance as measured by steady-state glucose levels after infusion of glucose, insulin and octreotide (to suppress endogenous insulin secretion). The conclusions of their study were that TAG and HDL were independently related to insulin resistance and the TAG/HDL ratio was the best predictor of insulin resistance. Of importance here is that the results showed that this ratio is comparable to the ATP III criteria for MetS in predicting insulin resistance and "even better in prediction the LDL phenotype B in two separate populations who were on different diets." This is, in fact, only the most recent of several studies (references in [8]) that have shown a correlation between TAG/HDL and insulin resistance and CVD risk as measured by LDL particle size. Table 2-4 as well as Figures 2 and 5 indicate that low $\mathrm{CHO}$ diets reliably reduce this marker. Inability to recognize this is again due to the separate conditions in which they are measured and the continued emphasis on reducing dietary fat above all else.

McLaughlin's analysis [8] identified a TAG/HDL ratio of $\geq$ 3.5 as a cutoff for identifying the insulin-resistant patient most at risk for CVD. It is of interest that in Foster's study [45] described above (Table 3; Figure 1), the average beginning values were 4.6 and 4.3 in the low $\mathrm{CHO}$ and low-fat arms, respectively, substantially above this cutoff value. After six months, the low $\mathrm{CHO}$ arm had reduced this marker to 3.7 while the LF group showed little change at 4.2. Similarly, in the Delta-1 study, neither the Step 1 diet nor the low fat diet were able to improve the TAG/ HDL ratio which was above the threshold value of 3.5 (Table 6)).

\section{Mechanism}

A recent review by Ginsberg [77] has provided an excellent description of the possible mechanisms and central role of insulin resistance in mediating the dyslipidemia of MetS. In combination with a proposal by Volek [13] on the mechanism for the reversal of this process, a reasonable understanding of the connection between MetS and $\mathrm{CHO}$ restriction is possible.

A primary target of insulin is hormone-sensitive lipase. Adipocyte insulin resistance, plausibly a down regulation of insulin response due to continued stimulation (from higher dietary $\mathrm{CHO}$ ), leads to increased lipolysis $[78,79]$. This will lead to greater delivery of fatty acids and an increase in hepatic esterification, and subsequent over production of VLDL, particularly the TAG-rich VLDL1. In combination with impaired plasma TAG clearance, a constant state of hypertriglyceridemia in the postabsorptive and postprandial period occurs. This leads to the exchange of TAG in VLDL for cholesteryl ester in LDL. The resulting TAG-rich LDL particle is a preferred substrate for hepatic lipase and lipoprotein lipase and thereby for generation of small, dense LDL. A similar neutral lipid exchange likely occurs with HDL whereby TAG-rich HDL is hydrolyzed by lipoprotein lipase resulting in the generation of smaller HDL particles that are rapidly removed from the circulation. In this way, elevated TAG resulting from disruption in insulin function, plays a central role in regulating the atherogenic dyslipidemia of MetS.

As noted above, Volek, et al. [13] have reviewed many studies showing that $\mathrm{CHO}$ restriction results in significant reductions in postprandial lipemia, and beneficial effects on HDL and intravascular processing of lipoproteins. A key component is what might be called the fatty acid paradox. Whereas insulin resistance is frequently characterized by high fatty acid levels, $\mathrm{CHO}$ restriction can improve insulin resistance while raising fatty acids. The latter effect is presumed to be due to lower insulin levels and disinhibition of hormone sensitive lipase. This is accompanied by enhanced cellular fatty acid uptake, mitochondrial transport and increased oxidation. The bias toward fat oxidation over storage reduces hepatic TAG and reduces synthesis and secretion of VLDL.

\section{Discussion}

A joint position statement by several organizations recommended "current dietary guidelines from the ADA, 
AHA and the NCEP-ATP III.... These recommendations may require modification, however, as new information is generated from additional diet intervention studies [80]." Rather than additional studies, however, we provide new information from an evaluation of papers already in the literature that may provide a basis for modification. Data compiled in Figures 2, 3, 4 show that low $\mathrm{CHO}$ diets improve the symptoms of MetS as defined by five common criteria. We propose that in addition to potential value as therapy, the response to $\mathrm{CHO}$ restriction might be considered an operational definition of MetS. Beyond formal categorizing, the idea is consistent with the generally held belief that MetS is intimately involved with some form of insulin resistance. (The importance of other factors such as inflammation are not mutually exclusive). Cornier et al. showed differential benefit of low $\mathrm{CHO}$ vs. low fat diets for people with or without insulin resistance [51]; this study might be thought of as a model for future work to follow this line of thinking. We emphasize that our main point is that an intimate connection between $\mathrm{CHO}$ restriction and the complex of symptoms of MetS is seen in the literature of both low $\mathrm{CHO}$ studies and low fat (higher $\mathrm{CHO}$ ) studies. Individual judgment as to the importance of MetS compared to other specific factors or more global assessments such as the Framingham criteria will determine how use is made of this connection. We do believe, however, that ignoring studies on $\mathrm{CHO}$ restriction would be unscientific and unproductive.

\section{How low is low carbohydrate?}

Goneril. What need you five-and-twenty, ten, or five...?

Regan. What need one?

- William Shakespeare, King Lear.

The data summarized here suggest that some degree of $\mathrm{CHO}$ restriction would provide a first line of attack against the symptoms of MetS. The principle of $\mathrm{CHO}$ restriction is that by keeping insulin low, metabolism is biased towards lipid oxidation rather than storage, or the effects of fatty acids on peripheral tissues. Most studies that reported deleterious effects of saturated fat have been carried out in the presence of high $\mathrm{CHO}$ and there is a real question whether such effects carry over into hypocaloric conditions or those where insulin is better controlled $[28,60,81,82]$.

In general, whereas current thinking in MetS emphasizes the consequences of insulin resistance, we feel that the role of CHO-induced hyperinsulinemia as a causative factor in generating the initial insulin resistance, dyslipidemia or obesity has been under-appreciated. In any case, there are now many ways to implement $\mathrm{CHO}$ restriction ranging from ketogenic diets (less than $50 \mathrm{~g} / \mathrm{d}$ ) to diets based on glycemic index, an indirect method of reducing insulin excursions. The question is how low is low? It is clear that $40 \% \mathrm{CHO}$ is better than $55 \%$ for MetS and there has been some reluctance to go lower even though the studies that have done so show continued improvement. Perusal of Table 2-4 suggests that the lower, the better. Insofar as pattern B is associated with insulin resistance and MetS, examination of Figure 4 supports this idea. The barriers to exploring lower $\mathrm{CHO}$ diets appears to be continued emphasis on low fat intake although it has been known since Keys's Seven Country study that total fat in the diet does not correlate with cardiovascular risk [38]. At least as indicated in its popular diet book, the No-Fad Diet [83], the American Heart Association has removed its limitation on total fat which should open the door to more flexible diet interventions. Since many studies have shown that there is frequently a spontaneous reduction in total caloric intake in very low $\mathrm{CHO}$ diets and that $\mathrm{CHO}$ removed is not replaced by fat or protein, very low $\mathrm{CHO}$ now appears as a far more prudent choice than judged in the past.

\section{Is this new?}

The phenomenon of CHO-induced hypertriglyceridemia is long established [84-88]. In addition, low fat diets are known to reduce, not only LDL, but also HDL levels. For example, the 2004 recommendations of the American Diabetic Association (ADA) state that "Low-saturated fat (i.e., $10 \%$ of energy) high carbohydrate diets increase postprandial levels of plasma glucose, insulin, triglycerides and, in some studies, decrease plasma HDL cholesterol when compared in metabolic studies to isocaloric high monounsaturated fat diets." This is our conclusion (our italics). We think the ADA statement could have been more clearly worded: "Substitution of $\mathrm{CHO}$ for monounsaturated fat "increase(s) postprandial levels of plasma glucose, insulin..." or could have been more comprehensive: "substitution of $\mathrm{CHO}$ or protein for fat increases..." In other words, it has been known for some time that low fat reduces HDL as well as LDL concentrations as described clearly in the Delta-1 study. Again, Rock's study that used the increase in TAG and decrease in HDL as a marker for compliance to a low fat diet supports the idea as an accepted principle.

In combination with the experimentally observed and intuitively obvious reduction in fasting blood glucose and insulin, our proposal for the importance of CHO replacement in the diet hardly seems new. Yet such an idea, to our knowledge has never been made explicit. The primacy of the low fat paradigm in traditional thinking may have played a role in ignoring this obvious correlation. However, we have, in various places, presented or summarized evidence that low $\mathrm{CHO}$ diets have a beneficial effect on MetS $[13,16]$ but the tight connection proposed here conceptually eluded us. Having raised the question, however, 
it is now clear that it is perfectly consistent with established knowledge.

\section{Is MetS useful?}

The intricacies of the debate among official agencies on the clinical importance of MetS [9] are beyond the scope of this article. As a first order approximation, however, we are inclined to follow Reaven's strategy in the Point/ Counterpoint paper $[10,89]$ for assessing the need for the concept of MetS. He describes a patient with a BMI of 27.8 $\mathrm{kg} / \mathrm{m}^{2}$ who would not conform to the WHO definition of MetS because of acceptable values of glucose, TAG and an HDL level of $37 \mathrm{mg} / \mathrm{dL}$ and he points out that if the HDL level fell to $33 \mathrm{mg} / \mathrm{dL}$ such a patent would fit a new criteria but would not sensibly be treated in a different way. Under the approach considered here, the patient with the higher HDL would be presented with a number of options for weight loss whereas the patient with lower HDL might reasonably be counseled to $\mathrm{CHO}$ restriction as a first strategy. We therefore think that MetS or some combination of markers by any other name would have much more virility than the description of MetS as Methuselah in his amusing Counterpoint [87]. We also side with the "Pro" position on the value for basic research. Reaven raises the critical question: "How can there be a common etiology for a diagnostic category based on satisfying 3 of 5 arbitrarily defined criteria when any combination of the 3 will define the same phenotype as any other trio of abnormalities.?" A plausible answer to this question is that if all the markers in MetS are related to hyperinsulinemia and/or insulin resistance, then the relative $\mathrm{K}_{\mathrm{m}}$ 's for insulin for the different target proteins and different tissues are likely to lead to a variable time course for specific individuals and markers are likely to exceed cutoff at different times for each patient. Appearance of one marker may then be indicative of other still silent conditions.

\section{Recommendations for the American population}

The data summarized here suggest that there is value in the definition of MetS and that a nutritional strategy based on CHO restriction might sensibly be the "default" diet, the first to be tried, for patients with MetS. In the case of normal weight individuals with MetS, CHO restriction may be the only effective non-pharmacological approach for treating the diversity of symptoms. The choice of any intervention, however, depends on individual assessment of the relative importance of different risk factors and our goal here is the establishment of the close link between CHO restriction and MetS rather than any recommendation.

The recent AHA/NHLBI Scientific Statement on Metabolic Syndrome $[90,91]$ as well as the ATP III emphasize as the primary target, $\mathrm{LDL}$, a marker that is not considered a feature of MetS and that may not even be high in many patients with MetS. Whereas nutritional recommendations are quite general (reduce weight, increase exercise), these reports emphasize a low fat diet (although limiting simple sugars). We think this is inconsistent and we have made the case that a low fat diet, if high in carbohydrate, seems to be widely accepted as raising TAG, lowering HDL and worsening glycemic control, seemingly the wrong thing for MetS. We also disagree with the assertion in the AHA/NHLBI statement that most low CHO diets are high in saturated fat. This statement is undocumented and, as noted in the introduction, essentially equates all reduced carbohydrate approaches and does not seem to distinguish between total and saturated fat. Even if it were true the statement avoids the question of the effect of saturated fat in the presence of low $\mathrm{CHO}$ or hypocaloric diets $[60,81,82,92]$. In practical terms, a recommendation to reduce saturated fat on low $\mathrm{CHO}$ diets might be more helpful than blanket prohibition. In addition, the AHA/ NHLBI report [90] presents the rationale for low $\mathrm{CHO}$ as the effect on appetite. Whereas this may be a component, it has been stated many times, and is part of basic biochemical education $[16,93-96]$, that the rationale of $\mathrm{CHO}$ restriction is the control of metabolism by insulin regulation. The effects described above clearly support this. Although we think that, within the framework of MetS, some recommendations can be made, in the end we are probably in agreement with Reaven's judgment that "What is required is less advice and more information [54]."

\section{Questions raised}

The data summarized here leave little room for doubt that the generally accepted deterioration in HDL and TAG levels with low fat diets and the established improvement in glycemic control with $\mathrm{CHO}$ restriction are part of a more general picture. The hypothesis that response to $\mathrm{CHO}$ restriction (because of the effect on insulin) is the defining feature of MetS is the proposed generalization. This idea raises several questions.

Is there a threshold level of $\mathrm{CHO}$ restriction that is necessary to elicit improvements in MetS? What is the effect of replacing the calories lost from $\mathrm{CHO}$ with protein or with fat, and in what proportion? How does this compare to not replacing them at all?

Does excessive CHO consumption cause MetS in susceptible individuals?

What is the relative risk in addressing MetS with $\mathrm{CHO}$ restriction compared to low fat diets for reduction in LDL? That is, what is the relative risk of high LDL vs. the symptoms that comprise MetS? 
What is the role of genotype in determining the response to $\mathrm{CHO}$ restriction?

\section{Summary}

Five symptoms common to most definitions of MetS are those that are reliably improved by $\mathrm{CHO}$ restriction. Carbohydrate restriction is one strategy for weight loss but, in addition, improves glycemic control, insulin levels, TAG and HDL levels even in the absence of weight loss. We suggest that response to $\mathrm{CHO}$ restriction may, in fact, be an operational definition of MetS. Its underlying basis would rest on the idea that the features of MetS are associated with a disruption in insulin metabolism which is strongly influenced by dietary $\mathrm{CHO}$. The extent to which this definition is useful may depend on its application by individual practitioners. Experimental studies that follow its lead or conversely disprove its fundamental premise should advance our understanding of obesity, diabetes and CVD. Dismissing CHO restriction without evidence, or expressing "concerns" rather than offering data will probably be less productive.

\section{Abbreviations}

Adult Treatment Panel (ATP III), American Diabetes Association (ADA), American Heart Association (AHA), Average American diet (AAD), carbohydrate (CHO), low fat (LF), Metabolic Syndrome (MetS), National Cholesterol Education Program (NCEP), triacylglycerol (TAG), World Health Organization (WHO)

\section{Competing interests}

The author(s) declare that they have no competing interests.

\section{Note}

Table 2 - Effect of carbohydrate restriction on markers for Metabolic Syndrome (See Table 2)

Data shown in bold indicate improvement in marker, plain, worsening. References:1. [97]; 2. [24]; 3. [98]; 4. [99]; 5. [100]; 6. [101]; 7. [42]; 8. [102]; 9. [103]; 10. [104]; 11. [74]; 12. [105]; 13. [23].

Table 3 - Effect of carbohydrate restriction on markers for Metabolic Syndrome under conditions of constant body mass (See Table 3 )

Data shown in bold indicate low $\mathrm{CHO}$ shows greater improvement in markers for MetS than LF; plain, LF is better. Table reference 3 shows the ratio of low $\mathrm{CHO}$ to LF. References: 1. [42]; 2. [43]; 3. [44].

Table 4 - Comparison of low CHO vs. LF diets on markers for Metabolic Syndrome (See Table 4)
Data shown in bold indicate low CHO (or mod-PROT) shows greater improvement in marker than LF; plain, LF is better. Experiment in reference [106] was carried out for a longer time period but diets became very similar. References:1. [107]; 2. [113]; 3. [46]; 4. [45]; 5. [108]; 6. [72]; 7. [109]; 8. [110]; 9. [111]; 10. [112]; 11. [73]; 12. [75]; 13. [59]; 14. [106].

\section{Table 6 - Outcomes of the Delta-1 study (See Table 6)}

Data from reference [64]. bold indicates improvement in the parameter from Step 1 or low Saturated Fat diet compared to $\mathrm{AAD}$; plain indicates worsening of parameter compared to AAD.

\section{References}

I. Eckel RH, Grundy SM, Zimmet PZ: The metabolic syndrome. Lancet 2005, 365(9468): 1415-1428.

2. Grundy SM, Brewer HBJ, Cleeman Jl, Smith SCJ, Lenfant C: Definition of metabolic syndrome: Report of the National Heart, Lung, and Blood Institute/American Heart Association conference on scientific issues related to definition. Circulation 2004, 109 (3):433-438.

3. Grundy SM, Hansen B, Smith SCJ, Cleeman JI, Kahn RA: Clinical management of metabolic syndrome: report of the American Heart Association/National Heart, Lung, and Blood Institute/American Diabetes Association conference on scientific issues related to management. Arterioscler Thromb Vasc Biol 2004, 24(2):el9-24.

4. Tonkin A: The metabolic syndrome -- a growing problem. European Heart Journal Supplements 2004, 6:A37-A42.

5. Aude YW, Mego P, Mehta JL: Metabolic syndrome: dietary interventions. Curr Opin Cardiol 2004, I 9(5):473-479.

6. Hanley AJ, Wagenknecht LE, D'Agostino RBJ, Zinman B, Haffner SM: Identification of subjects with insulin resistance and beta-cell dysfunction using alternative definitions of the metabolic syndrome. Diabetes 2003, 52(I I):2740-2747.

7. Hunt KJ, Resendez RG, Williams K, Haffner SM, Stern MP: National Cholesterol Education Program versus World Health Organization metabolic syndrome in relation to all-cause and cardiovascular mortality in the San Antonio Heart Study. Circulation 2004, I I 0(10): 1 25I- 1257.

8. McLaughlin T, Reaven G, Abbasi F, Lamendola C, Saad M, Waters D, Simon J, Krauss RM: Is there a simple way to identify insulinresistant individuals at increased risk of cardiovascular disease? Am J Cardiol 2005, 96(3):399-404.

9. Kahn R, Buse J, Ferrannini E, Stern M: The metabolic syndrome: time for a critical appraisal: joint statement from the American Diabetes Association and the European Association for the Study of Diabetes. Diabetes Care 2005, 28(9):2289-2304.

10. Grundy SM: Point: the metabolic syndrome still lives. Clin Chem 2005, 5 I (8): I352-1354.

II. Reaven GM: The metabolic syndrome: requiescat in pace. Clin Chem 2005, 5 I(6):93I-938.

12. Arora SK, McFarlane SI: The case for low carbohydrate diets in diabetes management. Nutr Metab (Lond) 2005, 2:16.

13. Volek JS, Sharman MJ, Forsythe CE: Modification of lipoproteins by very low-carbohydrate diets. J Nutr 2005, 135(6): I339-1342.

14. Third Report of the National Cholesterol Education Program (NCEP) Expert Panel on Detection, Evaluation, and Treatment of High Blood Cholesterol in Adults (Adult Treatment Panel III) final report. Circulation 2002, 106(25):3 I 43-342I.

15. Ashen MD, Blumenthal RS: Clinical practice. Low HDL cholesterol levels. N Engl J Med 2005, 353( ( 2): I 252- I 260.

16. Feinman RD, Makowske M: Metabolic Syndrome and Low-Carbohydrate Ketogenic Diets in the Medical School Biochemistry Curriculum. Metabolic Syndrome and Related Disorders 2003, I:189-198. 
17. Westman EC, Yancy Jr. WS, Haub MD, Volek JS: Insulin Resistance from a Low-Carbohydrate, High Fat Diet Perspective. Metabolic Syndrome and Related Disorders 2005, 3:3-7.

18. Ruderman N, Chisholm D, Pi-Sunyer X, Schneider S: The metabolically obese, normal-weight individual revisited. Diabetes 1998, 47(5):699-713.

19. Willet W: Increasing prevalence of overweight among US adults. The National Health and Nutrition Examination Surveys, I960 to I99I. JAMA I994, 272:205-2II.

20. Poppitt SD, Keogh GF, Prentice AM, Williams DE, Sonnemans HM Valk EE, Robinson E, Wareham NJ: Long-term effects of ad libitum low-fat, high-carbohydrate diets on body weight and serum lipids in overweight subjects with metabolic syndrome. Am J Clin Nutr 2002, 75(I): I I-20.

21. Enns CK, Goldman JD, Cook A: Trends in Food and Nutrient Intakes by Adults: NFCS 1977-78, CSFII I989-9I, and CSFII 1994-95. Family Economics and Nutrition Review 1997, I0:2-15.

22. Kennedy ET, Bowman SA, Powell R: Dietary-fat intake in the US population. J Am Coll Nutr 1999, I 8(3):207-2I2.

23. Boden G, Sargrad K, Homko C, Mozzoli M, Stein TP: Effect of a lowcarbohydrate diet on appetite, blood glucose levels, and insulin resistance in obese patients with type 2 diabetes. Ann Intern Med 2005, I 42(6):403-4 I I.

24. Larosa JC, Fry AG, Muesing R, Rosing DR: Effects of high-protein, low-carbohydrate dieting on plasma lipoproteins and body weight. I Am Diet Assoc 1980, 77(3):264-270.

25. Miller BV, Bertino J, Reed TG, Burrington C, Davidson LK, Green A, Gartung A, Nafziger A: An Evaluation of the Atkins' Diet. Metabolic Syndrome and Related Disorders 2003, I:299-309.

26. Bray GA: The epidemic of obesity and changes in food intake: the Fluoride Hypothesis. Physiol Behav 2004, 82(I): I | 5- I 2 I.

27. Martin WF, Armstrong LE, Rodriguez NR: Dietary Protein Intake and Renal Function. Nutr Metab (Lond) 2005, 2(I):25.

28. Van der Auwera I, Wera S, Van Leuven F, Henderson ST: A ketogenic diet reduces amyloid beta 40 and 42 in a mouse model of Alzheimer's disease. Nutr Metab (Lond) 2005.

29. Veech RL: The therapeutic implications of ketone bodies: the effects of ketone bodies in pathological conditions: ketosis, ketogenic diet, redox states, insulin resistance, and mitochondrial metabolism. Prostaglandins Leukot Essent Fatty Acids 2004, 70(3):309-319.

30. Veech RL, Chance B, Kashiwaya Y, Lardy HA, Cahill GFJ: Ketone bodies, potential therapeutic uses. IUBMB Life 200I, 5 I (4):24I-247.

31. Brand-Miller JC: Glycemic index in relation to coronary disease. Asia Pac J Clin Nutr 2004, I3(Suppl):S3.

32. Brand-Miller JC: Postprandial glycemia, glycemic index, and the prevention of type 2 diabetes. Am J Clin Nutr 2004 80(2):243-244.

33. Atkins RC: Dr. Atkins' New Diet Revolution. New York, Avon Books; 2002

34. Agatston A: The South Beach Diet. New York, Random House; 2003.

35. Eades MR, Eades MD: Protein Power. New York, Bantam Books; 1996.

36. Hu FB, Manson JE, Willett WC: Types of dietary fat and risk of coronary heart disease: a critical review. J Am Coll Nutr 200I, 20(I):5-19.

37. Hu FB, Stampfer MJ, Manson JE, Rimm E, Colditz GA, Rosner BA Hennekens $\mathrm{CH}$, Willett WC: Dietary fat intake and the risk of coronary heart disease in women. $N$ Engl J Med 1997, 337(2I): |49|-|499.

38. Keys A: Coronary heart disease in seven countries. 1970, 4I (Suppl): I-2II.

39. Feinman RD, Fine Ej: Thermodynamics and Metabolic Advantage of Weight Loss Diets. Metabolic Syndrome and Related Disorders 2003, I:209-219.

40. Volek JS, Westman EC: Very-low-carbohydrate weight-loss diets revisited. Cleve Clin J Med 2002, 69(I I):849, 853, 856-8 passim.

41. Westman EC, Mavropoulos J, Yancy WS, Volek JS: A Review of Low-carbohydrate Ketogenic Diets. Curr Atheroscler Rep 2003, 5(6):476-483.

42. Sharman MJ, Kraemer WJ, Love DM, Avery NG, Gomez AL, Scheett TP, Volek JS: A ketogenic diet favorably affects serum biomar- kers for cardiovascular disease in normal-weight men. J Nutr 2002, I 32(7): | 879- I 885

43. Volek JS, Sharman MJ, Gomez AL, Scheett TP, Kraemer WJ: An Isoenergetic Very Low-Carbohydrate Diet Is Associated With Improved Serum High-Density Lipoprotein Cholesterol (HDL-C), Total Cholesterol to HDL-C Ratio, Triacylglycerols, and Postprandial Lipemic Responses Compared to a Low-Fat Diet in Normal Weight, Normolipidemic Women. J Nutr 2003, I33(9):2756-276 I

44. Allick G, Bisschop PH, Ackermans MT, Endert E, Meijer AJ, Kuipers F, Sauerwein HP, Romijn JA: A low-carbohydrate/high-fat diet improves glucoregulation in type 2 diabetes mellitus by reducing postabsorptive glycogenolysis. J Clin Endocrinol Metab 2004, 89(12):6193-6197.

45. Foster GD, Wyatt HR, Hill JO, McGuckin BG, Brill C, Mohammed BS, Szapary PO, Rader DJ, Edman JS, Klein S: A randomized trial of a low-carbohydrate diet for obesity. N Engl I Med 2003 , 348(2I):2082-2090.

46. Samaha FF, Iqbal N, Seshadri P, Chicano KL, Daily DA, McGrory J, Williams T, Williams M, Gracely EJ, Stern L: A low-carbohydrate as compared with a low-fat diet in severe obesity. N Engl J Med 2003, 348(2I):2074-208I

47. Feinman RD, Fine EJ: "A Calorie is a calorie" violates the second law of thermodynamics. Nutrition Journal 2004, 3(9):.

48. Feinman RD, Fine EJ: Whatever happened to the second law of thermodynamics? Am J Clin Nutr 2004, 80(5): | 445-6; author reply 1446.

49. Fine EJ, Feinman RD: Thermodynamics of weight loss diets. Nutr Metab (Lond) 2004, I(I): I 5

50. Bray GA, Champagne CM: Beyond energy balance: there is more to obesity than kilocalories. J Am Diet Assoc 2005, I 05(5 Suppl I):SI7-23.

5I. Cornier MA, Donahoo WT, Pereira R, Gurevich I, Westergren R, Enerback S, Eckel PJ, Goalstone ML, Hill JO, Eckel RH, Draznin B: Insulin sensitivity determines the effectiveness of dietary macronutrient composition on weight loss in obese women. Obes Res 2005, I 3(4):703-709.

52. Golay A, Eigenheer C, Morel Y, Kujawski P, Lehmann T, de Tonnac N: Weight-loss with low or high carbohydrate diet? Int / Obes Relat Metab Disord 1996, 20(I 2): 1067-1072.

53. Poe EA: The Purloined Letter. http://xroadsvirginiaedu/ HYPER/ POE/purloinehtml I845.

54. Reaven GM: Effect of dietary carbohydrate on the metabolism of patients with non-insulin dependent diabetes mellitus. Nutr Rev 1986, 44(2):65-73.

55. Gannon MC, Nuttall FQ, Saeed A, Jordan K, Hoover H: An increase in dietary protein improves the blood glucose response in persons with type 2 diabetes. Am / Clin Nutr 2003, 78(4):734-74 I.

56. Nuttall FQ, Gannon MC: Metabolic response of people with type 2 diabetes to a high protein diet. Nutr Metab (Lond) 2004 , I(I):6.

57. Gannon MC, Nuttall FQ: Effect of a high-protein, low-carbohydrate diet on blood glucose control in people with type 2 diabetes. Diabetes 2004, 53(9):2375-2382

58. Ludwig DS, Jenkins DJ: Carbohydrates and the postprandial state: have our cake and eat it too? Am J Clin Nutr 2004, 80(4):797-798

59. McAuley KA, Hopkins CM, Smith KJ, McLay RT, Williams SM, Taylor RW, Mann Jl: Comparison of high-fat and high-protein diets with a high-carbohydrate diet in insulin-resistant obese women. Diabetologia 2005, 48(I):8-16.

60. Feinman R: When is a high fat diet not a high fat diet? Nutrition \& Metabolism 2005, 2(27):

61. Garg A, Bantle JP, Henry RR, Coulston AM, Griver KA, Raatz SK Brinkley L, Chen YD, Grundy SM, Huet BA, et al:: Effects of varying carbohydrate content of diet in patients with non-insulindependent diabetes mellitus. Jama | 994, 27 | ( I 8): | 42 |- | 428.

62. Mensink RP, Zock PL, Kester AD, Katan MB: Effects of dietary fatty acids and carbohydrates on the ratio of serum total to HDL cholesterol and on serum lipids and apolipoproteins: a meta-analysis of 60 controlled trials. Am J Clin Nutr 2003, 77(5): I | 46-I I55.

63. Rock CL, Flatt SW, Thomson CA, Stefanick ML, Newman VA, Jones L, Natarajan L, Pierce JP, Chang RJ, Witztum JL: Plasma triacylglycerol and HDL cholesterol concentrations confirm self- 
reported changes in carbohydrate and fat intakes in women in a diet intervention trial. J Nutr 2004, 134(2):342-347.

64. Ginsberg HN, Kris-Etherton P, Dennis B, Elmer PJ, Ershow A, Lefevre M, Pearson T, Roheim P, Ramakrishnan R, Reed R, Stewart K, Stewart $P$, Phillips K, Anderson N: Effects of reducing dietary saturated fatty acids on plasma lipids and lipoproteins in healthy subjects: the DELTA Study, protocol I. Arterioscler Thromb Vasc Biol 1998, 18(3):44I-449.

65. Gordon DJ, Knoke J, Probstfield JL, Superko R, Tyroler HA: Highdensity lipoprotein cholesterol and coronary heart disease in hypercholesterolemic men: the Lipid Research Clinics Coronary Primary Prevention Trial. Circulation 1986, 74: 12 I7-I225.

66. Berglund L, Oliver EH, Fontanez N, Holleran S, Matthews K, Roheim PS, Ginsberg HN, Ramakrishnan R, Lefevre M: HDL-subpopulation patterns in response to reductions in dietary total and saturated fat intakes in healthy subjects. Am J Clin Nutr 1999, 70(6): $992-1000$

67. Volek JS, Sharman MJ: Cardiovascular and hormonal aspects of very-low-carbohydrate ketogenic diets. Obes Res 2004, 12 Suppl 2: I I5S-23S.

68. Lamarche B, Tchernof A, Moorjani S, Cantin B, Dagenais GR, Lupien PJ, Despres JP: Small, dense low-density lipoprotein particles as a predictor of the risk of ischemic heart disease in men. Prospective results from the Quebec Cardiovascular Study. Circulation 1997, 95(1):69-75.

69. Dreon DM, Fernstrom HA, Miller B, Krauss RM: Low-density lipoprotein subclass patterns and lipoprotein response to a reduced-fat diet in men. Faseb J 1994, 8(I): $121-126$.

70. Krauss RM: Dietary and Genetic Probes of Atherogenic Dyslipidemia. Arterioscler Thromb Vasc Biol 2005.

71. Krauss RM: Atherogenic lipoprotein phenotype and diet-gene interactions. J Nutr 200I, 13 I (2):340S-3S.

72. Sharman MJ, Gomez AL, Kraemer WJ, Volek JS: Very low-carbohydrate and low-fat diets affect fasting lipids and postprandial lipemia differently in overweight men. J Nutr 2004, 134(4):880-885.

73. Aude YW, Agatston AS, Lopez-Jimenez F, Lieberman EH, Marie A, Hansen M, Rojas G, Lamas GA, Hennekens CH: The national cholesterol education program diet vs a diet lower in carbohydrates and higher in protein and monounsaturated fat: a randomized trial. Arch Intern Med 2004, 164(19):2।4I-2I46.

74. Hays JH, DiSabatino A, Gorman RT, Vincent S, Stillabower ME: Effect of a high saturated fat and no-starch diet on serum lipid subfractions in patients with documented atherosclerotic cardiovascular disease. Mayo Clin Proc 2003, 78( I I): |33|-|336.

75. Seshadri P, Iqbal N, Stern L, Williams M, Chicano KL, Daily DA, McGrory J, Gracely EJ, Rader DJ, Samaha FF: A randomized study comparing the effects of a low-carbohydrate diet and a conventional diet on lipoprotein subfractions and C-reactive protein levels in patients with severe obesity. Am J Med 2004, I I 7(6):398-405.

76. Dreon DM, Fernstrom HA, Williams PT, Krauss RM: A very low-fat diet is not associated with improved lipoprotein profiles in men with a predominance of large, low-density lipoproteins. Am J Clin Nutr 1999, 69(3):4II-4I8.

77. Ginsberg HN, Zhang YL, Hernandez-Ono A: Regulation of plasma triglycerides in insulin resistance and diabetes. Arch Med Res 2005, 36(3):232-240.

78. Boden G, Shulman GI: Free fatty acids in obesity and type $\mathbf{2}$ diabetes: defining their role in the development of insulin resistance and beta-cell dysfunction. Eur J Clin Invest 2002, 32 Suppl 3:14-23.

79. Zammit VA: Insulin stimulation of hepatic triacylglycerol secretion in the insulin-replete state: implications for the etiology of peripheral insulin resistance. Ann N Y Acad Sci 2002, 967:52-65.

80. Klein S, Burke LE, Bray GA, Blair S, Allison DB, Pi-Sunyer $X$, Hong $Y$, Eckel $\mathrm{RH}$ : Clinical implications of obesity with specific focus on cardiovascular disease: a statement for professionals from the American Heart Association Council on Nutrition, Physical Activity, and Metabolism: endorsed by the American College of Cardiology Foundation. Circulation 2004, I I 0( I 8):2952-2967.

81. Mozaffarian D, Rimm EB, Herrington DM: Dietary fats, carbohydrate, and progression of coronary atherosclerosis in postmenopausal women. Am J Clin Nutr 2004, 80(5): I I75-I I 84.
82. Volek JS, Forsythe CE: The case for not restricting saturated fat on a low carbohydrate diet. Nutr Metab (Lond) 2005, 2:21.

83. American Heart Association: No-Fad Diet. A Personal Plan fo Healthy Weight Loss. New York, Clarkson Potter; 2005.

84. Hellerstein MK: Carbohydrate-induced hypertriglyceridemia: modifying factors and implications for cardiovascular risk. Curr Opin Lipidol 2002, I 3(1):33-40.

85. Hudgins LC: Effect of high-carbohydrate feeding on triglyceride and saturated fatty acid synthesis. Proc Soc Exp Biol Med 2000, 225(3): 178- I83.

86. Hudgins LC, Hellerstein M, Seidman C, Neese R, Diakun J, Hirsch J: Human fatty acid synthesis is stimulated by a eucaloric low fat, high carbohydrate diet. J Clin Invest 1996, 97(9):208I-209I.

87. Parks EJ, Hellerstein MK: Carbohydrate-induced hypertriacylglycerolemia: historical perspective and review of biological mechanisms. Am J Clin Nutr 2000, 7 I (2):4I 2-433.

88. Parks EJ, Krauss RM, Christiansen MP, Neese RA, Hellerstein MK: Effects of a low-fat, high-carbohydrate diet on VLDL-triglyceride assembly, production, and clearance. J Clin Invest 1999, 104(8): 1087-1096.

89. Reaven G: Counterpoint: just being alive is not good enough. Clin Chem 2005, 5 I (8): I $354-$ I 357.

90. Grundy SM, Cleeman II, Daniels SR, Donato KA, Eckel RH, Franklin BA, Gordon DJ, Krauss RM, Savage PJ, Smith SCJ, Spertus JA, Costa F: Diagnosis and Management of the Metabolic Syndrome. An American Heart Association/National Heart, Lung, and Blood Institute Scientific Statement. Circulation 2005.

91. Grundy SM, Cleeman JI, Daniels SR, Donato KA, Eckel RH, Franklin BA, Gordon DJ, Krauss RM, Savage PJ, Smith SCJ, Spertus JA, Costa F: Diagnosis and Management of the Metabolic Syndrome. An American Heart Association/National Heart, Lung, and Blood Institute Scientific Statement. Executive Summary. Circulation 2005

92. Knopp RH, Retzlaff BM: Saturated fat prevents coronary artery disease? An American paradox. Am J Clin Nutr 2004, 80(5): I I02-II03.

93. Pogozelski W, Arpaia N, Priore S: The Metabolic Effects of Lowcarbohydrate Diets and Incorporation into a Biochemistry Course. Biochemistry and Molecular Biology Education 2005, 33:91-100.

94. Harris RA, Crabb DW: Chapter 22. Metabolic Interrelationships. In Textbook of Biochemistry With Clinical Correlations Sixth edition. Edited by: Devlin TM. New York, John Wiley \& Sons, Inc.; 2006.

95. Makowske M, Feinman RD: Nutrition education: a questionnaire for assessment and teaching. Nutr / 2005, 4(I):2.

96. Smith C, Marks AD, Lieberman M: Basic Medical Biochemistry: A Clinical Approach. 2nd edition. Philadelphia , Lippincott Williams \& Wilkins; 2005.

97. Rickman F, Mitchell N, Dingman J, Dalen JE: Changes in serum cholesterol during the Stillman diet. Jama 1974, 228(I):54-58.

98. Phinney SD, Horton ES, Sims EA, Hanson JS, Danforth EJ, LaGrange BM: Capacity for moderate exercise in obese subjects after adaptation to a hypocaloric, ketogenic diet. J Clin Invest 1980, 66(5): || $52-|| 6 \mid$

99. Phinney SD, Bistrian BR, Evans WJ, Gervino E, Blackburn GL: The human metabolic response to chronic ketosis without caloric restriction: preservation of submaximal exercise capability with reduced carbohydrate oxidation. Metabolism 1983, 32(8):769-776.

100. Newbold HL: Reducing the serum cholesterol level with a diet high in animal fat. South Med J 1988, 8I(I):6I-63.

I0I. Volek JS, Gomez AL, Kraemer WJ: Fasting lipoprotein and postprandial triacylglycerol responses to a low-carbohydrate diet supplemented with $\mathbf{n - 3}$ fatty acids. I Am Coll Nutr 2000, I9(3):383-39I.

102. Meckling KA, Gauthier M, Grubb R, Sanford J: Effects of a hypocaloric, low-carbohydrate diet on weight loss, blood lipids, blood pressure, glucose tolerance, and body composition in free-living overweight women. Can J Physiol Pharmacol 2002, 80(I I): $1095-1105$

103. Westman EC, Yancy WS, Edman JS, Tomlin KF, Perkins CE: Effect of 6-month adherence to a very low carbohydrate diet program. Am J Med 2002, I I 3(I):30-36.

104. Dashti HM, Bo-Abbas YY, Asfar SK, Mathew TC, Hussein T, Behbahani A, Khoursheed MA, Al-Sayer HM, Al-Zaid NS: Ketogenic diet 
modifies the risk factors of heart disease in obese patients. Nutrition 2003, 19(10):901-902.

105. Dashti HM, Mathew TC, Hussein T, Asfar SK, Behbahani A, Khoursheed MA, Al-Sayer HM, Bo-Abbas YY, Al-Zaid NS: Long-term effects of a ketogenic diet in obese patients. Exp Clin Cardiol 2004, 9(3):200-205.

106. Dansinger ML, Gleason JA, Griffith JL, Selker HP, Schaefer EJ: Comparison of the Atkins, Ornish, Weight Watchers, and Zone diets for weight loss and heart disease risk reduction: a randomized trial. Jama 2005, 293(I):43-53.

107. Brehm BJ, Seeley RJ, Daniels SR, D'Alessio DA: A randomized trial comparing a very low carbohydrate diet and a calorierestricted low fat diet on body weight and cardiovascular risk factors in healthy women. J Clin Endocrinol Metab 2003, 88(4): $1617-1623$.

108. Volek JS, Sharman MJ, Gomez AL, Judelson DA, Rubin MR, Watson G, Sokmen B, Silvestre R, French DN, Kraemer WJ: Comparison of energy-restricted very low-carbohydrate and low-fat diets on weight loss and body composition in overweight men and women. Nutr Metab (Lond) 2004, I ( I): I3.

109. Brehm BJ, Spang SE, Lattin BL, Seeley RJ, Daniels SR, D'Alessio DA: The role of energy expenditure in the differential weight loss in obese women on low-fat and low-carbohydrate diets. J Clin Endocrinol Metab 2004.

1 10. Meckling KA, O'Sullivan C, Saari D: Comparison of a low-fat diet to a low-carbohydrate diet on weight loss, body composition, and risk factors for diabetes and cardiovascular disease in free-living, overweight men and women. J Clin Endocrinol Metab 2004, 89(6):27I7-2723.

I I I. Stern L, Iqbal N, Seshadri P, Chicano KL, Daily DA, McGrory J, Williams M, Gracely EJ, Samaha FF: The effects of low-carbohydrate versus conventional weight loss diets in severely obese adults: one-year follow-up of a randomized trial. Ann Intern Med 2004, I 40( I 0):778-785.

1 12. Yancy WSJ, Olsen MK, Guyton JR, Bakst RP, Westman EC: A lowcarbohydrate, ketogenic diet versus a low-fat diet to treat obesity and hyperlipidemia: a randomized, controlled trial. Ann Intern Med 2004, I 40(10):769-777.

\section{Publish with Bio Med Central and every scientist can read your work free of charge}

"BioMed Central will be the most significant development for disseminating the results of biomedical research in our lifetime. "

Sir Paul Nurse, Cancer Research UK

Your research papers will be:

- available free of charge to the entire biomedical community

- peer reviewed and published immediately upon acceptance

- cited in PubMed and archived on PubMed Central

- yours - you keep the copyright

Submit your manuscript here:

http://www.biomedcentral.com/info/publishing_adv.asp
BioMedcentral 